\title{
Using peers to improve sexual and reproductive health and rights of young people living with HIV in Uganda: Findings from a Link Up evaluation
}

Population Council

Follow this and additional works at: https://knowledgecommons.popcouncil.org/departments_sbsr-hiv

Part of the Demography, Population, and Ecology Commons, Family, Life Course, and Society Commons, Gender and Sexuality Commons, and the International Public Health Commons How does access to this work benefit you? Let us know!

\section{Recommended Citation}

Population Council. 2016. "Using peers to improve sexual and reproductive health and rights of young people living with HIV in Uganda: Findings from a Link Up evaluation," Link Up Study Brief. Washington, DC: Population Council. 
Globally, efforts to prevent HIV transmission have been showing substantial gains among adults. However, it is estimated that onethird of new HIV cases worldwide now occur among young people (adolescents and young adults between the ages of 15 and 24). ${ }^{1}$ Even though long-term HIV-related health outcomes are improving overall, adolescents and young adults represent the only group of people living with HIV (PLHIV) for whom HIV-related mortality has increased since the year 2000; globally, HIV is now the second leading cause of death among adolescents. ${ }^{2,3}$ The problem is most critical in eastern and southern Africa, where 61 percent of all young people living with HIV (YPLHIV) currently reside. ${ }^{4}$ As with most countries in sub-Saharan Africa, the HIV epidemic in Uganda is generalized, and national prevalence is estimated at 7.3 percent. ${ }^{1,5}$ Of the 1.5 million PLHIV in Uganda, 170,000 are between the ages of 15-24, and the disease affects young women over twice as frequently (4.9 percent) as young men (2.1 percent). ${ }^{5,6}$ Uganda's rate of new HIV infections among 15- to 24-year-olds is among the highest in the world-second only to South Africa. ${ }^{3}$

Just like any other young person, Ugandan YPLHIV want to have boyfriends or girlfriends, enjoy healthy sex lives, and eventually many want to have children at a time of their choosing. ${ }^{7-9}$ Nevertheless, many gaps remain in the care and support services available to adolescents living with HIV. Program planners and health care providers frequently neglect the needs and desires of these young people, and many YPLHIV have outgrown pediatric services, but feel uncomfortable in existing adult services. ${ }^{7,10}$

Thus, while access to antiretroviral therapy (ART) improves, many YPLHIV do not take their medication as prescribed. ${ }^{10,11}$ Poor adherence has been shown to impede viral suppression, lead to treatment failure, and ultimately undermine the use of treatment as prevention. ${ }^{11-14}$ In addition, Ugandan YPLHIV often lack respectful counseling and clinical services, and trustworthy sources of information. As a result, they may have a poor understanding of

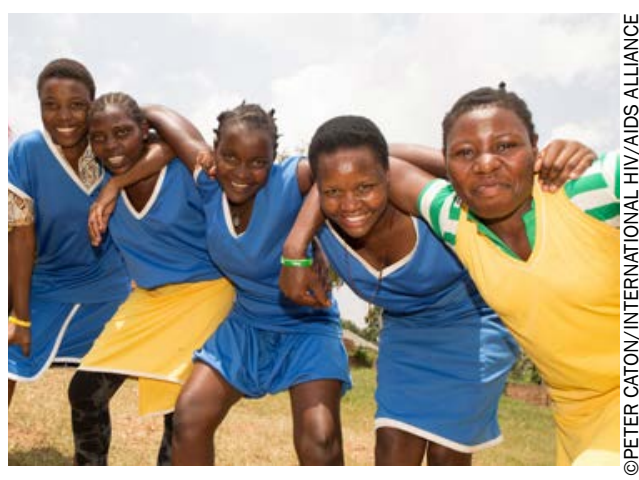

Through the Link Up project, the Population Council in partnership with Makerere University's CHDC evaluated Link Up activities that sought to increase YPLHIV access to comprehensive HIV and SRHR services

\section{KEY MESSAGES}

Young people living with HIV have complex sexual, reproductive health and HIV/STI needs.

Peer support groups can be a valuable source of social support and can facilitate healthy behaviors and increase health service utilization among young people living with HIV.

Concerns about stigma and confidentiality, along with structural barriers like stock-outs, can deter young people living with HIV from seeking the care they need. 
HIV transmission, and engage in behaviors like non-disclosure of HIV status and inconsistent condom use that may accelerate sexually transmitted infection (STI) and HIV transmission, or increase the risk of unintended pregnancies. ${ }^{7,15}$

Given this context, programs for YPLHIV should address not only their immediate HIV care needs but also their broader sexual and reproductive health and rights (SRHR). ${ }^{9}$ In addition, efforts intended to support YPLHIV must overcome structural barriers to care-seeking, including stigma, service linkages, supply shortages, and providers' attitudes toward adolescents and young people. Link Up, a global consortium led by the

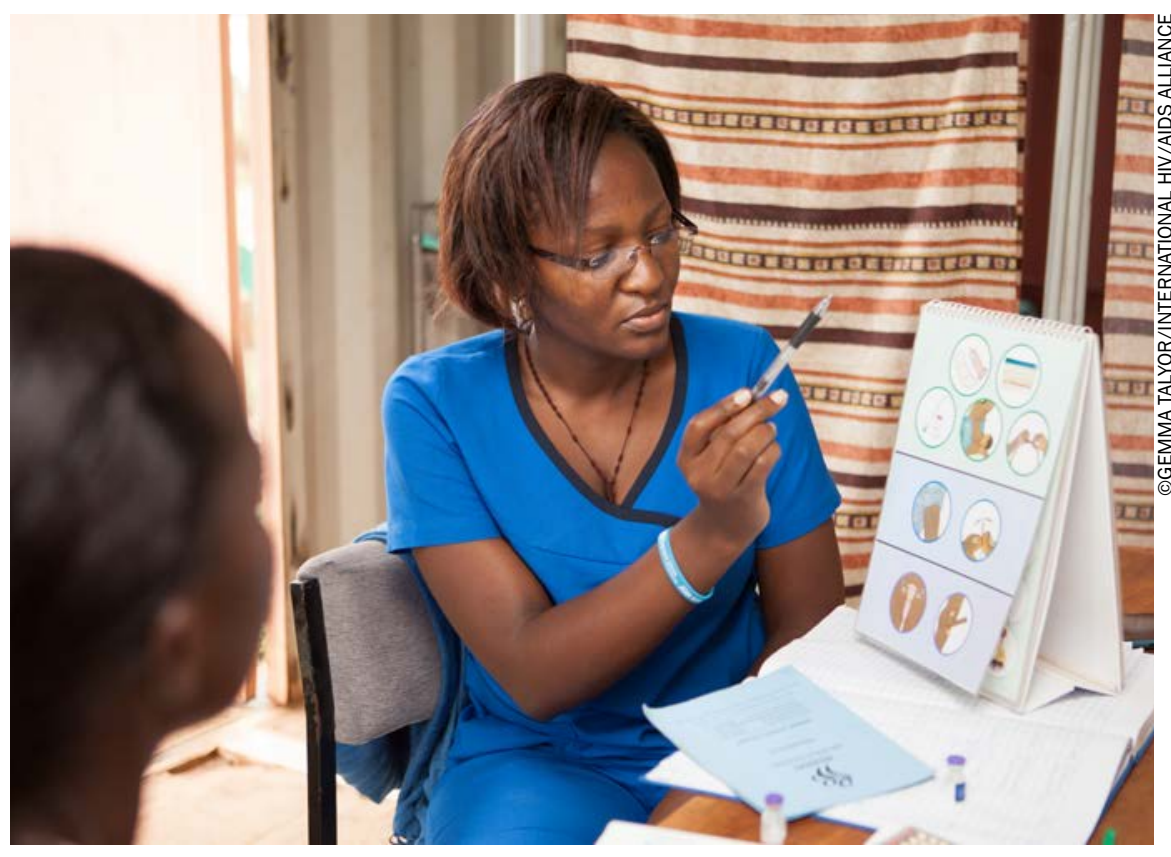

Link Up delivered health education, counseling, and peer support tailored to the needs of YPLHIV in order to educate and empower them recognize their sexual and reproductive health and rights, and feel confident in seeking health services.

International HIV/AIDS Alliance, sought to meet these needs by creating linkages between comprehensive community- and facility-based HIV and SRHR services. In addition, Link Up delivered health education, counseling, and peer support tailored to the needs of YPLHIV in order to educate and empower them to recognize their rights, and feel confident in seeking health services. In this brief, we present findings from the Population Council's evaluation of Link Up activities among YPLHIV in Uganda.

\section{METHODS}

\section{Description of the intervention}

Link Up trained peer educators to connect with networks of new and existing YPLHIV peer support groups, where they would provide health education and counseling, and link YPLHIV to facility-based HIV and SRHR services. Optimally, support groups met between one and two times each month, and were safe spaces where YPLHIV could openly discuss their needs and concerns, and exchange strategies to lead healthier lives. During group meetings, Link Up peer educators provided health education and counseling on topics relevant to YPLHIV, including relationships, fertility awareness, safe conception, preventing HIV and STI transmission, HIV-related stigma, and the rights of YPLHIV to obtain comprehensive SRHR and HIV services. The peer educators also led income-generating activities.

Twelve health facilities provided HIV and SRHR services to YPLHIV under the Link Up project. These facilities were selected based on their proximity to peer support groups in the Link Up network, and were operated by either Marie Stopes International Uganda (MSIU), or the Ugandan Ministry of Health (MoH). $\mathrm{MoH}$-run facilities often collaborated with other local Link Up implementing partners. Link Up-trained peer educators and community health workers distributed referral vouchers to YPLHIV, which they could redeem at Link Up partner facilities for HIV care and SRHR services. The vouchers were designed with input from young Ugandans to accomplish three goals: 1) generate demand for services by being attractive and removing cost barriers; 2) help young clients navigate the healthcare system; and 3) capture an easy-toremember unique identifying code in order to monitor service utilization.

Finally, to foster a supportive atmosphere and reduce the social barriers to care-seeking that YPLHIV often 
experience, the project trained physicians and nurses in participating facilities to prioritize the needs of YPLHIV and deliver confidential HIV and SRHR services in a respectful, non-stigmatizing manner. Link Up also strengthened the supply chain by helping facilities to prevent stock-outs of health commodities. Furthermore, a youth-friendly corner was set up at each of the 12 participating facilities, where young clients could collect educational material or meet with peer educators who were on hand to provide individual or group counseling services.

\section{Data collection}

The Population Council, in partnership with Makerere University's Child Health and Development Centre (CHDC), conducted an evaluation of Link Up efforts to increase YPLHIV access to comprehensive HIV and SRHR services. In January 2015, we visited Link Up peer support group meetings in Nakasongola and Luwero districts and recruited 473 YPLHIV between the ages of 15 and 24 to participate in a baseline survey. We followed this cohort through September 2015. After the end of the nine-month intervention period, we successfully re-interviewed 350 of our original participants. Key outcomes of interest included selfefficacy to engage in healthy behaviors, comprehensive
HIV knowledge, condom use at last sex, HIV status disclosure, ART uptake and adherence, STI services uptake, and contraceptive prevalence. ART adherence was self-reported, and defined as not having missed any ART dose within the past 14 days. HIV disclosure was measured by asking whether a participant had disclosed their HIV status to a regular or casual sexual partner.

To inform clinical and counseling practice at the participating facilities, we also conducted mystery client (MC) observations at ten Link Up partner health facilities. Each selected facility was visited twice during March $2015(n=20)$. We trained four young adults aged 22-24 to complete these audits by assuming one of several different MC scenarios. In each scenario, MCs were sexually active young adults seeking one of three types of services: ART $(n=6)$, HIV counseling and testing (HCT) $(n=6)$, and family planning (FP) services $(n=8)$. During four visits the MCs were male, and during 12 visits the MCs portrayed YPLHIV.

At the end of the project, we conducted qualitative interviews among 34 YPLHIV who had participated in the surveys to gauge their experience using health services at Link Up partner facilities. To improve our understanding of peer educator and healthcare

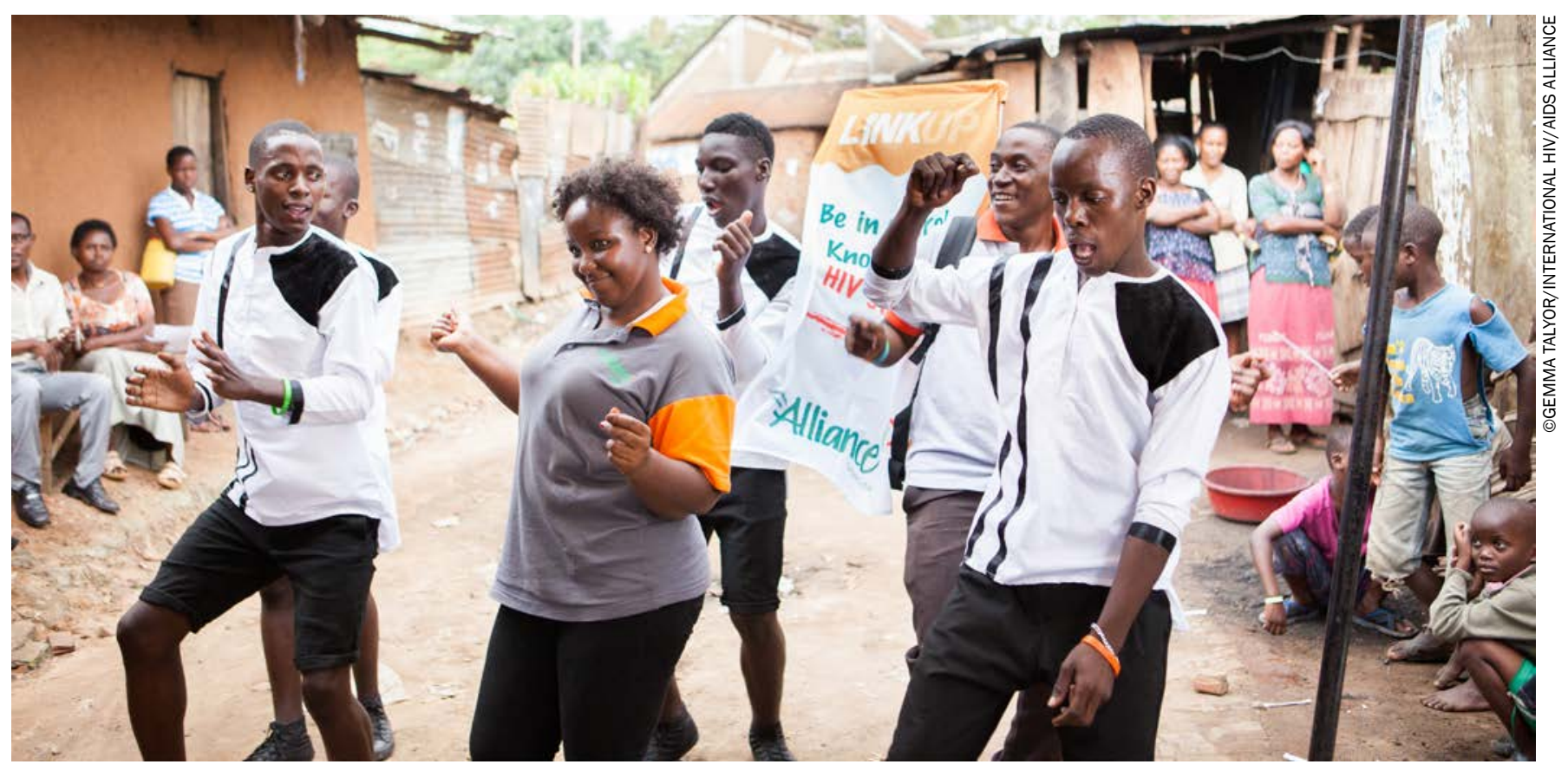

Daphine, 19, a peer educator on SRHR issues in Uganda, dances with other peer educators. Peer support groups were central to the Link Up intervention for YPLHIV. 
provider experiences with Link Up, we also conducted in-depth interviews with 10 peer educators who are living with HIV, and eight facility providers.

\section{Data analysis}

To assess changes in key indicators among YPLHIV between baseline to endline, we analysed the data of 350 cohort participants who completed both baseline and endline surveys. Adjusted odds ratios from multiple logistic regression (random effects) are reported to compare key outcomes at baseline and endline. MCs audits were analysed using descriptive statistics. We also present key findings from in-depth interviews to contextualize descriptive statistics with experiences with the Link Up project, as reported by YPLHIV, peer educators, and providers.

\section{RESULTS}

\section{Participant characteristics}

More than two-thirds (70 percent) of participants were women, 67 percent had never been married, 48 percent had completed some primary education, and 46 percent had completed some secondary education; nearly one-third of the sample were unemployed (28 percent). Over two-thirds (68 percent) were currently on ART, and 69 percent reported having a CD4 count test at least once in the past 12 months. About three-quarters ( 76 percent) of the sample had ever had sex, among whom over three quarters ( 77 percent) had not disclosed their HIV status to a sexual partner (Table 1). Detailed information on the sample characteristics and key SRHR indicators can be found in previous publications. ${ }^{16}$

\section{Results from the mystery client audit}

MCs reported areas for improvement in the facilities visited. Wait times were often long, and in about half of facility visits, MCs rated Link Up health facilities as being accessible ( 55 percent) or comfortable ( 45 percent) during their visits. A similar proportion reported receiving client-centered (55 percent) and confidential (40 percent) care, respectively. Even though MCs reported that they were satisfied or very satisfied with the services they received at less than half ( 40 percent) of the visits, 80 percent of MCs indicated that

\begin{tabular}{lc}
\hline & $\%(\mathrm{n})$ \\
\hline Sex & \\
Male & $29.6(140)$ \\
$\quad$ Female & $70.4(333)$ \\
Education & \\
$\quad$ Some primary/completed primary & $49.5(234)$ \\
$\quad$ Secondary or above & $50.5(239)$ \\
Marital status & \\
$\quad$ Single/never married & $67.4(319)$ \\
$\quad$ Married/cohabitating & $21.4(101)$ \\
Separated/divorced & $11.2(53)$ \\
Had a living child/children & \\
$\quad$ Yes & $44.2(205)$ \\
No & $55.8(259)$ \\
Ever had sex & \\
$\quad$ Yes & $75.9(359)$ \\
No & $24.1(114)$ \\
Currently on ART & \\
Yes & $67.7(320)$ \\
No & $32.3(153)$ \\
Had a CD4 test in the past 12 months & \\
Yes & $68.5(324)$ \\
No & $31.5(149)$ \\
\hline
\end{tabular}

Whenever you get there, the doctor

might share about a number of issues,

so whatever you have not clearly under-

stood, you can ask while in the group be-

cause there is no such a thing as getting

ashamed. You can ask her and then she

explains to you thoroughly wherever you

have not understood. In case you fail to

understand, she will re-explain until you

have understood.. 


\section{Providers' perspectives about Link Up}

Link Up was unanimously appreciated by providers as drawing attention to youth needs and linking HIV/STI services with SRHR services, particularly in government-operated facilities.

They got know that at least every Thursday we sit with them only the youths as the youth friendly day.... We used to sit with them and they could explain to us the problems they face. We could also talk about family planning plus STI management...We have been treating STIs in the youth with these drugs which have been provided by these people of Link Up. In case we have ran out of stock then we replace it with the drugs of Link Up. They are providing us with family planning methods... Like the implants, because government injects in [inserts] very few of these methods, so if they are over we can try to use these of Link Up.

-Service provider, Nakasongola

they would return to the facility for care as well as recommend the facility to a friend.

\section{Exposure to intervention activities at endline}

The peer-led aspects of the project had excellent coverage (Table 2). Almost all participants (97 percent) reported that they had heard or seen information about the Link Up project. Similarly, 94 percent of participants had attended a peer support group meeting at least once in the past nine months; 91 percent reported that they were currently active members of in a peer support group, and 86 percent had been contacted by a peer educator during the intervention period. Just under half (49 percent) received a referral voucher for facility-based HIV and SRHR services from a peer educator, the majority of whom (81 percent) ultimately used the voucher to acquire health services. During the nine-month intervention period, half of study participants made five or more visits to a health facility.

I think having thing like these seminars

can make young people like us stronger.

I was so fearful, but when I attended

those seminars, I became stronger.

Without them, you can get worried...

Each can tell the other, "what is your

condition now?”, “when are you going

back to pick your medicines?", one can

say "we need to work", "what are you

rearing?", then one will say "I rear chick-

en," then the other will say "I am going

to do this." So we keep on sharing ideas.

TABLE 2 INTERVENTION EXPOSURE (PAST 9 MONTHS) $(\mathrm{N}=350$ )

\begin{tabular}{lc}
\hline & $\%$ \\
\hline Had heard or seen any information about the Link Up project & $94.8(332)$ \\
Had attended any peer support group meetings & $94.3(330)$ \\
Currently attends peer support group meetings & $88.0(308)$ \\
Had contact with a Link Up peer educator & $79.1(277)$ \\
Received a referral voucher for HIV and SRHR services from a Link Up peer educator & $47.7(167)$ \\
Used the referral voucher to seek health care* & $81.4(136)$ \\
\hline
\end{tabular}

*Among those who received a referral 
During qualitative interviews, participants indicated that Link Up peer support groups created a welcoming space where YPLHIV felt comfortable sharing the challenges faced in their daily lives, and learned new health risk-reduction strategies. Beyond health-related topics, the support groups often included incomegenerating activities, which may have generated additional interest and contributed to participant retention in their support groups.

\section{Remaining barriers to healthy living}

\section{Stigma and discrimination}

Some YPLHIV described being treated differently (not normal) in their homes, school, work, and community because of their HIV status.

Children at school tease a lot. For example, he can ask you what you are doing at school since you have HIV and you are going to die. And fear of discrimination.... You can fear to work in a hotel because once your boss gets to know that you are HIV positive they can restrict you or stop you from touching certain things. ...Such things make me feel bad.... People should consider people with HIV as normal people....

\section{-Married female, Luwero}

\section{Barriers to HIV-status disclosure}

Many young people did not disclose their status to others, or they chose to tell some people (e.g., parent), but not others (e.g., intimate partner). For unmarried young people who were not born with HIV and contracted it through sexual activity, disclosure was even more difficult given the stigma attached to premarital sex.

It's what I am thinking about, if I tell him [husband] that I am HIV positive, I am sure that he will chase me [away] and tell people about it. I would love to [tell him] but that is where my fear is.

-Married female, Nakasongola

\section{Effects of the intervention on key outcomes: baseline and endline comparison of cohort participants}

At baseline, many participants had misconceptions regarding HIV transmission, not only between partners, but also from mothers to their newborns; many assumed that by having a negative sex partner, they would be able to have healthy babies. ${ }^{16}$ To reduce knowledge gaps and share accurate information, Link Up incorporated individual and group counseling content intended not only to increase HIV-related knowledge, but to simultaneously improve self-efficacy and comfort in speaking with healthcare providers. Both of which are important intermediate factors in facilitating behavior change and improving service utilization among YPLHIV. By endline, participants showed significant improvements in comprehensive knowledge of HIV, self-efficacy, HIV disclosure, and condom use at last sex (Table 3).

\section{It brings me confidence in my heart}

that I am not alone in the world.

-Married male, Nakasongola

In addition, our analyses showed significant increases in the uptake of clinical HIV, STI, and FP services, including utilization of STI testing and screening, ART uptake, ART adherence, routine CD4 count testing, and use of modern contraceptives. Link Up-trained service providers at participating facilities to treat young clients respectfully and to create youth-friendly corners where peer educators can approach YPLHIV for health education purposes. This training, combined with demand created by peer educators, likely contributed to the observed increases in service utilization (Table $3)$. 
TABLE 3 EFFECTS OF THE INTERVENTION ON KEY OUTCOMES $(\mathrm{N}=350)$

\begin{tabular}{|c|c|c|}
\hline Key Outcomes & AOR & $(95 \% \mathrm{Cl})$ \\
\hline $\begin{array}{l}\text { Had comprehensive knowl- } \\
\text { edge of HIV }\end{array}$ & 1.8 & $(1.29-2.61)^{* * *}$ \\
\hline $\begin{array}{l}\text { Had high level of self- } \\
\text { efficacy for using condoms } \\
\text { and contraceptives }\end{array}$ & 1.8 & $(1.30-2.55)^{* * *}$ \\
\hline $\begin{array}{l}\text { Disclosed HIV status to sex } \\
\text { partner }\end{array}$ & 1.6 & $(1.01-2.55)^{*}$ \\
\hline Used condom at last sex & 1.7 & $(1.18-2.51)^{* *}$ \\
\hline $\begin{array}{l}\text { Received STI services (past } \\
6 \text { months) }\end{array}$ & 2.1 & $(1.46-2.89)^{* * *}$ \\
\hline Currently on ART & 2.5 & $(1.61-4.01)^{* * *}$ \\
\hline $\begin{array}{l}\text { Adherence to ART (self- } \\
\text { report, past } 14 \text { days) }\end{array}$ & 2.5 & $(1.3-4.9)^{* *}$ \\
\hline $\begin{array}{l}\text { Received CD4 test at least } \\
\text { once in past } 12 \text { months }\end{array}$ & 2.4 & $(1.54-3.61)^{* * *}$ \\
\hline Using modern FP methods & 1.7 & $(1.1-2.7)^{*}$ \\
\hline
\end{tabular}

$\mathrm{AOR}=$ Adjusted odds ratio comparing endline to baseline All analyses were adjusted for sex, age, education, marital status, and number of living children

$* p<0.05 ; * * p<0.01 ; * * * p<0.001$

\section{CONCLUSIONS AND RECOMMENDATIONS}

The intervention model described in this brief appears to have been effective in improving knowledge and self-efficacy for healthy living, increasing condom use, and increasing the utilization of SRHR and HIV services among YPLHIV. Peer support groups were central to the Link Up intervention for YPLHIV. These support groups were described as safe and supportive environments where YPLHIV could talk about their concerns and health needs, and learn strategies to manage stress, maintain prescribed drug regimens, and incorporate safer HIV and SRHR practices into current and future relationships. Moreover, by providing referrals to facility-based HIV and SRHR services, the peer educators were able to link YPLHIV to youth-friendly services, and help them more easily navigate their local health system.

Challenges were also noted in providing facilitybased services for YPLHIV. Mystery client audits indicated that preventing commodity shortages, reducing wait times, and modifying hours of operation to accommodate young people's school and work schedules can make services more accessible to YPLHIV. Facilities can increase client comfort by ensuring that waiting rooms are clean, well lit, and not too crowded. HIV-related stigma continues to be a factor that affects YPLHIV self-efficacy and healthcare access. Confidentiality is critical: YPLHIV fear rumors spreading about their HIV status, which both reinforces hesitancy to disclose their status and increases a desire to seek care at a time or place where YPLHIV are less likely to be recognized. Training should be provided to healthcare workers serving YPLHIV to enable them to deliver comprehensive SRHR and HIV services in a sensitive and respectful manner.

\section{REFERENCES}

1. UNAIDS. 2014. “The gap report." Geneva, Switzerland: Joint United Nations Programme on HIV/ AIDS.

2. - 2015. "Fact sheet 2015." Geneva, Switzerland: Joint United Nations Project on HIV/AIDS.

3. - 2013. "Global AIDS report, 2013." Geneva, Switzerland: Joint United Nations Project on HIV/ AIDS.

4. Idele, P. et al. 2014. "Epidemiology of HIV and AIDS among adolescents: Current status, inequities, and data gaps," Journal of Acquired Immune Deficiency Syndromes 66 (Supplement 2): S144-153.

5. Uganda Bureau of Statistics and ICF International. 2012. "Uganda Demographic and Health Survey 2011." Kampala, Uganda and Calverton, Maryland: Uganda Bureau of Statistics and ICF International.

6. Uganda Ministry of Health and ICF International. 2011. “Uganda AIDS Indicator Survey 2011." Kampala, Uganda and Calverton, Maryland: Uganda Bureau of Statistics and ICF International.

7. Birungi, H., et al. 2009. “Preventive service needs of young people perinatally infected with HIV in Uganda," AIDS Care 21(6): 725-731.

8. Oliveras, Elizabeth and Frederick Makumbi. 2013. "Addressing unmet need for contraception among HIV-positive women: Baseline survey results." Watertown, MA: Pathfinder International.

9. GNP+ and UNAIDS. 2011. "Positive health dignity and prevention operational guidelines." Geneva and Amsterdam: Global Network of People Living with HIV and UNAIDS. 
10. Adejumo, Olurotimi A. et al. 2015. “Contemporary issues on the epidemiology and antiretroviral adherence of HIV-infected adolescents in sub-Saharan Africa: A narrative review," Journal of the International AIDS Society 18(1)

11. Nachega, Jean B. et al. 2009. "Antiretroviral therapy adherence, virologic and immunologic outcomes in adolescents compared with adults in Southern Africa," Journal of Acquired Immune Deficiency Syndromes 51(1): 65-71.

12. Martin, M. et al. 2008. "Relationship between adherence level, type of the antiretroviral regimen, and plasma HIV type 1 RNA viral load: A prospective cohort study," AIDS Research and Human Retroviruses 24(10): 1263-1268.

13. Nabukeera-Barungi, Nicolette et al. 2015.

"Adherence to antiretroviral therapy and retention in care for adolescents living with HIV from 10 districts in Uganda," BMC Infectious Diseases 15: 520.
14. Sethi, Ajay K. et al. 2003. "Association between adherence to antiretroviral therapy and human immunodeficiency virus drug resistance," Clinical Infectious Diseases 37(8): 1112-1118.

15. Biddlecom, A. E. et al. 2007. “Adolescents' views of and preferences for sexual and reproductive health services in Burkina Faso, Ghana, Malawi and Uganda," African Journal of Reproductive Health 11(3): 99-110.

16. Population Council. 2015. "Sexual and reproductive health and rights among young people living with HIV in Uganda: Findings from the Link Up baseline survey," Link Up Brief. Washington, DC: Population Council.

\section{LINKUP}

Link Up aims to improve the sexual and reproductive health and rights (SRHR) of one million young people affected by HIV across five countries in Africa and Asia. The project is being implemented by a consortium of partners led by the International HIV/AIDS Alliance.

\section{For more information, visit www.link-up.org}

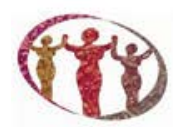

ATHENA

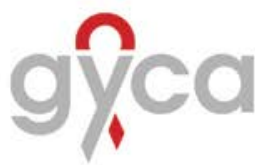

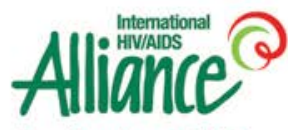

Together to end AIDS

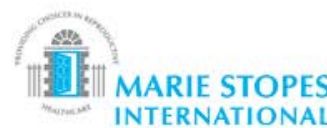

INTERNATIONAL

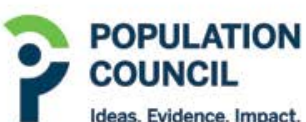

STOP AIDS

Ideas. Evidence. Impact.
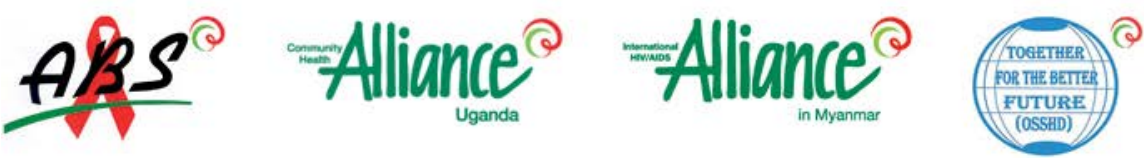

Government of the Netherlands Funded by the Ministry of Foreign Affairs of the government of the Netherlands.

POPULATION COUNCIL

Ideas. Evidence. Impact.
The Population Council confronts critical health and development issues-from stopping the spread of HIV to improving reproductive health and ensuring that young people lead full and productive lives. Through biomedical, social science and public health research in about 50 countries, the Council works with our partners to deliver solutions that lead to more effective policies, programs, and technologies to improve lives worldwide. Established in 1952 and headquartered in New York, the Council is a nongovernmental, nonprofit organization with an international board of trustees.

Suggested citation: Population Council. 2016. "Using peers to improve sexual and reproductive health and rights of young people living with HIV in Uganda: findings from a Link Up evaluation,” Link Up Study Brief. Washington, DC: Population Council.

www.popcouncil.org

(c) 2016 The Population Council, Inc. 